\title{
Связи с общественностью в парадигме цифровой экономики
}

\author{
Владимир Горохов \\ Марина Шилина
}

Концепция цифровой экономики обусловливает предпосылки для перехода российских связей с общественностью, которые выполняют маркетинговые функции, в разряд стратегически значимых для экономики и общества индустрий.

В статье проанализированы трансформации моделей маркетинговой, пиар- и стратегической коммуникации в парадигме цифровизации, датификации, цифровой экономики. Представленные теоретико-методологические основания исследования позволяют определить параметры функционирования российского пиара в условиях цифровой асимметрии коммуникации.

Ключевые слова: российская модель датифицированной конвергенции экономических и социальных отношений, квадроспираль цифровой экономики, цифровой нормативный базисный субъект, бесшовная трансформация, омнипрофессиональная модель социальной коммуникации.

(C) Горохов Владимир Маркович доктор филологических наук, профессор, заведующий кафедрой рекламы и связей с общественностью факультета журналистики МГУ имени М.В. Ломоносова (г. Москва, Россия), reklama202@mail.ru

(C) Шилина Марина Григорьевна доктор филологических наук, профессор кафедры рекламы, связей с общественностью и дизайна РЭУ имени Г.В. Плеханова, доцент кафедры рекламы и связей с общественностью МГУ имени М.В. Ломоносова (г. Москва, Россия), marina.shilina@gmail.com

\section{Введение}

В конце 2010 гг. экономика и общество становятся нормативно цифровыми: во всем мире принимаются национальные и международные стратегии цифровизации (напр., «Цифровая экономика Российской Федерации» (2017-2024)1; G20 Ministerial Statement on Trade and Digital Economy, 20192). Дигитализация определяет амбивалентные эффекты в экономике цифрового капитализма (Schiller, 1999; Zuboff, 2019) и социума, в частности более высокие темпы развития производства и при этом рост социального неравенства вследствие цифрового разрыва (англ. digital divide), обусловленного проблемами с доступом граждан к технологиям, их использованию, получению выгод и т.д.

Цифровизация на текущем этапе опосредована большими данными (англ. big data, data-driven). Впервые в истории капитализма формируется особая датифицированная конвергенция: экономические отношения, основанные на анализе обширных массивов данных, оказываются неотделимы от отношений социальных и в большинстве случаев равнозначны им. Формируется новейшая форма капитализма - датифицированный капитализм (data capitalism (West, 2019)), появляются датифицированные отношения в социуме (data relations (Couldry, Mejias, 2019)), а также радикально иное, датифициро- 
ванное, цифровое неравенство (Shilina, Gorokhov, 2019).

В российской государственноцентричной модели цифровой (датифицированной) экономики (ЦЭ) целью является получение глобальных конкурентных преимуществ; основными инструментами названы датифицированные технологии, базовыми акторами - государство, бизнес, научнообразовательное сообщество и граждане («Цифровая экономика РФ»З), так называемая квадроспираль цифровой экономики (Федюнин, Шилина, 2019; Шилина, 2012).

Впервые в новейшей отечественной истории предполагается участие россиян в модернизации как равноправных субъектов, нормативное включение социума в ЦЭ определяет специфику российской модели датифицированной конвергенции экономических и социальных отношений.

В модель ЦЭ наряду с обозначенными выше акторами включаются цифровые нормативные прямые и опосредованные субъекты: традиционные (например, программы и владельцы ИКТ, цифровых платформ и т.д.) и новые (подключенные «вещи», субъекты Интернета и их владельцы, владельцы платформ, данных, дата-хабов и т.п.). Полисубъектность цифровой датифицированной модели коммуникации расширяется за счет новых прямых цифровых субъектов, например подключенных «вещей» (их количество к 2025 г. вырастет, по различным прогнозам, до 30-50 млн4).

Ключевой проблемой реализации нормативных программ ЦЭ в условиях подобного многоуровневневого гибридного мультисубъектного взаимодействия оказывается доверие между всеми участниками, что зафиксировано в нормативных документах (напр., G20 Ministerial Statement on Trade and Digital Economy, 2019) и исследованиях (Шилина, Вартанов, 2019; Zerfass, Verčič, Verhoeven, Moreno et al., 2019).

Релевантным инструментом обеспечения эффективных интеракций всех акто- ров в ЦЭ могут стать институциональные связи с общественностью (СО), пиар (англ. public relations) как «стратегия доверия» (Буари, 2001).

Отметим, что 2689 ведущих экспертовпрактиков пиара из почти трех десятков европейских стран, включая Россию, в последние годы называют цифровую датификацию (технологии на основе big data, в частности искусственный интеллект и т.д.) и доверие одним из главных вызовов индустрии (Zerfass, Verčič, Verhoeven, Moreno et al., 2019).

Также связи с общественностью, согласно зарубежным исследованиям, могут действительно стать стратегически значимым социальным институтом, развивая участие граждан в процессах инноваций и лидерства (Zerfass, Huck, 2007) и равноправной стратегической коммуникации (Hallahan, Holtzhausen, Van Ruler, Verčič et al., 2007).

В России связи с общественностью индустрия на стадии становления, начавшая формироваться после распада СССР. До настоящего времени пиар традиционно выполняет не стратегические, а маркетинговые функции (Шилина, 2016 (а)). Так, в 2019 г., согласно индустриальным исследованиям агентства Buman Media, маркетинговые инструменты пиар-специалисты определили в числе наиболее востребованных 5 .

Эффективное взаимодействие акторов, как и формирование доверия, в пиаре реализуются по классической модели симметричной коммуникации. Однако в условиях цифровизации (особенно в Интернете) равноправное взаимодействие проблематично, поскольку цифровая коммуникация априори асимметрична благодаря участию цифровых базисных субъектов (ЦБС) - прямых (программы/ цифровая интернет-среда и т.д.) и опосредованных (владельцы ИКТ, цифровых платформ и т.д.) (Шилина, 2007, 2012). 
В условиях датификации полисубъектность увеличивается, следовательно, усиливается и асимметрия. Особые коммуникативные проблемы возникают при имплементации в индустриальные практики технологий искусственного интеллекта (Шилина, 2019; Gentsch, 2019 (a, b); Zerfass, Verčič, Verhoeven, Moreno et al., 2019), которые с 2019 г. становятся нормативными в России ${ }^{6}$.

Итак, концепция цифровой экономики обусловливает предпосылки для трансформации связей с общественностью в стратегически значимую для экономики и общества индустрию и, значит, провоцирует повышение институциональной значимости пиара. Для российских СО это определяет проблему перехода от маркетинговой парадигмы коммуникации к стратегической в реальном и цифровом пространстве.

Таким образом, целью исследования становится решение выявленной научной проблемы - определение в парадигме цифровой экономики параметров российских связей с общественностью как потенциально стратегической коммуникации.

\section{Теоретико-методологические основания изучения СО в парадигме цифровой экономики}

Решение научной проблемы исследования определяет необходимость проведения компаративного анализа особенностей и моделей маркетинга, связей с общественностью и стратегических коммуникаций в парадигме российской цифровой экономики - в квадроспирали ЦЭ.

В отечественной пиарологии связи с общественностью в условиях цифровизации, цифровые модели связей с общественностью как объект начинают исследоваться в 2010 гг., однако до настоящего времени эта проблематика представлена в основном в отдельных сферах (Быков, 2013), в учебных пособиях (Быков,
Филатова (ред.), 2010; Чумиков, Горошко, Кремнев, 2019).

Исследования по проблематике big data, актуальной коммуникации, опосредованной большими данными (data-driven, datafied), data-driven-технологий в пиаре, связей с общественностью в цифровой экономике немногочисленны, начали появляться сравнительно недавно, носят теоретический характер (Володенков, 2019; Федюнин, Шилина, 2019; Шилина, 2016 (6); Shilina, You, 2019).

Зарубежные ученые публикуют работы по цифровизации пиара с 1990 гг., изучение связей с общественностью в условиях датификации развивается с середины 2010 гг. Сегодня авторы затрагивают актуальные аспекты датифицированного пиара как стратегической коммуникации (Ihlen, Fredriksson (eds.), 2018; Flyverbom, Deibert, Matten, 2019; Holtzhausen, 2016; Holtzhausen, Zerfass, 2015; Verčič D., Verčič A., Sriramesh, 2015; Wiesenberg, Tench, 2019; Wiesenberg, Zerfass, Moreno, 2017). Появляются масштабные исследования, например уровня имплементации технологий на основе данных, особенностей работы профессиональных коммуникаторов в условиях цифровизации и датификации (Zerfass, Verčič, Verhoeven, Moreno et al., 2019) и т.д. Особое внимание уделяют ученые амбивалентным эффектам актуальной коммуникации, опосредованной большими данными (Davidson, 2016; Falkheimer, Heide, 2018; Huang Y., Wu, Huang Q., 2017), в частности, программами искусственного интеллекта (Gentsch, 2019 (a, b)).

Концепция и модели актуальных маркетинговых коммуникаций (МК) в Интернете представлены в обширном пласте отечественных исследований, посвященных вовлечению потребителей в онлайнвзаимодействие с компанией ${ }^{7}$ и в процесс создания потребительской ценности (см.: Смирнов, Шадрова, 2010; Минаев, 2016; Окольнишникова, 2011 и др.). Однако ис- 
следования моделирования взаимодействия субъекта и объекта в российской цифровой датифицированной экономике с коммуникативных позиций пока не представлены.

Особенности стратегической коммуникации (СК) в России только начинают обсуждаться в академическом сообществе (Богданов, 2017). Отечественные авторы относят модели СК к политической и бизнессфере (Гавра, 2015). За рубежом, несмотря на активизацию исследований с появлением «Международного журнала стратегической коммуникации» (The International Journal of Strategic Communication) и публикации программных статей (Hallahan, Holtzhausen, Van Ruler, Verčič et al., 2007), не так много авторов включается в исследовательский дискурс о СK (Nothhaft, 2016). Тем не менее актуальные особенности стратегической коммуникации систематизированы в последние несколько лет ведущими европейскими учеными (Falkheimer, Heide, 2018; Nothhaft, Werder, Verčič, Zerfass (eds.), 2019; van Ruler, 2018; van Ruler, Korver., 2019), что позволяет на основе этих изысканий представить в данной статье модель актуальной стратегической коммуникации.

Отметим, что в академическом дискурсе о связях с общественностью, несмотря на неопределенность и дискуссионность сущности, целеполагания и функционирования СО, сформировались два общепринятых и при этом взаимоисключающих постулата, существенные для нашего исследования. Во-первых, исследователи пиара в развитых индустриях настаивают, что связи с общественностью не являются маркетинговой коммуникацией, обладают своеобычными характеристиками и «должны быть функцией менеджмента, отдельной от других функций» (Grunig J., Grunig L., Toth (eds.), 2006: 310). Во-вторых, в растущем количестве исследований зафиксировано отсутствие четких границ между связями с общественностью и другими областями профессиональной социальной коммуникации, такими как интегрированный коммуникационный менеджмент, маркетинг или корпоративные коммуникации (см. напр., van Ruler, Verčič (eds.), 2004).

В целом новизна и дискуссионность выявленной научной проблемы трансформации отечественных связей с общественностью в парадигме цифровой датифицированной экономики определяет отсутствие комплексных работ и релевантных общепризнанных концепций по заявленной теме, что в условиях нормативности стратегий и сжатых сроков реализации программ российской ЦЭ обусловливает необходимость оперативной научной рефлексии.

\section{Методы и дизайн исследования}

Решение научной проблемы исследования определяет гипотезу $\mathrm{Hl}$ (если в условиях цифровой экономики предполагается трансформация модели отечественных связей с общественностью из маркетинговой в стратегическую, то институциональный статус СО повышается), и поиск ответов на следующие вопросы: RQ1: Каковы коммуникативные особенности цифровой датифицированной экономики? RQ2: Каковы характеристики связей с общественностью в парадигме цифровой экономики при переходе от маркетинговой к стратегической модели?

Отсутствие релевантных теоретикометодологических концепций по заявленной проблематике в зарубежной и отечественной пиарологии обусловливает проведение на первом этапе кабинетного исследования для формирования концептуальной рамки изучения российского пиара в цифровой датифицированной экономике, включая изучение в парадигме цифровой экономики коммуникативных особенностей взаимодействия акторов, 
моделей маркетинговой и стратегической коммуникации, характеристик модели цифрового доверия как стратегии связей с общественностью.

Далее, согласно методологии изучения имплементации инноваций (Grant, 2016), предполагается выявление особенностей феномена институционального пиара в парадигме цифровой экономики на основе экспертных оценок (интервью и форсайтсессия (Холод, 2018) с академическими $(n=5)$ и индустриальными $(n=5)$ экспертами (2019). Форсайт-сессия с исследователями и практиками позволяет проанализировать на основе составленных карт восприятия обеими группами экспертов особенности развития связей с общественностью в парадигме цифровой экономики по двум основным параметрам: особенности и применение в индустрии датифицированной цифровой коммуникации и уровень ее воздействия на индустрию и институт СО.

\section{Цифровизация, датификация и смена парадигмы социальной коммуникации}

Цифровизация (Negroponte, 1996) как преобразование различной информации в цифровую форму сегодня трактуется все более широко и становится все более человекоразмерной ичеловекоцентричной. На смену информатизации и использованию компьютеров и информационных технологий для решения отдельных технопроблем пришли возможности формирования целостных технологических сред (платформ, экосистем), где непосредственно пользователь может создавать нужный ему формат взаимодействия (от технологического до бизнес-партнерского) для решения любых сложных задач (Козырев, 2018).

Человекоцентричность и человекоразмерность становятся отправными точками для оценки актуальных особенностей и эффективности цифровизации кактаковой, поскольку для развития и экономики, и технологий последние должны быть доступны и использоваться как специалистами, так и рядовыми гражданами; доступны должны быть не только технологии, но и результаты их внедрения; пользователи должны иметь навыки работы с цифровой информацией ит.д. (Халин, Чернова, 2018). В веб после кризиса интернет-индустрии на рубеже веков в так называемом формате 2.0 тестирование, использование технологий и ресурсов массовой аудиторией является обязательным условием, в частности для их дальнейшей технической оптимизации, просьюмеры становятся активными создателями контента и равноправными субъектами интернет-коммуникации.

Расширение функций рядового пользователя и усиление участия граждан в процессах цифровизации становится базовым условием признания их эффективности. Так, индексы цифровизации экономики и общества отражают в первую очередь уровень участия граждан. Согласно наиболее комплексному европейскому Индексу цифровизации экономики и общества DESI (Digital Economy and Society Index) ${ }^{8}$, с участием граждан связано больше всего параметров: сразу за оценкой «подключения» страны к результатам цифровизации связи (connectivity), оценивают человеческий капитал (human capital/digital skills), использование Интернета гражданами (use of Internet by citizens), цифровые публичные услуги (digital public services) и т.д.

Несмотря на технические, экономические и административные предпосылки для фокусировки модели цифровизации на рядового пользователя, цифровое неравенство по-прежнему остается проблемой. В частности, в РФ, несмотря на растущее количество пользователей Интернета (по данным Mediascope, 93 млн человек в 2019 г.9, по данным РАЭК - 95,9 млн $\left.{ }^{10}\right)$, оте- 
чественные и зарубежные исследователи отмечают, что в российских регионах цифровое неравенство все еще существует (Gladkova, Ragnedda, 2019).

Цифровая датификация как преобразование различных форматов исходных данных в данные машиночитаемые и доступные для компьютерной обработки и аналитики (big data), уже на начальном этапе сбора больших социальных данных (big social data) провоцирует усиление неравенства и социальные проблемы. Так, основа цифровизации и датификации в обществе - цифровая доступность и прозрачность персональных данных - расцениваются всё чаще как нарушение прав и свобод индивида и социума (Greenfield, 201811; Pagallo, 2017).

Сложности с защитой персональных данных граждан, отсутствие у них компетенций, невозможность получения итогов анализа данных (что исключает доступ рядовых пользователей к уровню создания смыслов и получению выгод), провоцируют датифицированное цифровое неравенство (Shilina, Gorokhov, 2019).

Датифицированное цифровое неравенство усугубляет гибридизация коммуникационной сферы, где подключенных «вещей» становится больше, чем людей, что определяет новые параметры человекомашинной и межмашинной коммуникации и провоцирует новые форматы неравноправного, несимметричного взаимодействия акторов в цифровой сфере.

Расширение применения цифровизации и Интернета, усиление датификации ведет к концентрации и контролю за доступом к информации владельцев ИКТ, платформ, дата-хабов и т.д. (Zuboff, 2019).

Итак, новейшие форматы цифровизации, опосредованной большими данными, формируют максимально удобные условия для массовой аудитории просьюмеров, которые генерируют пользовательский контент и становятся полноправны- ми субъектами интернет-коммуникации. Однако парадокс человекоцентричности развития цифровых технологий заключается в том, что с расширением доступа граждан, аудиторий к цифровым ресурсам и технологиям в условиях датификации, модель цифровой коммуникации (априори иерархическая) становится все более асимметричной. Подобную ситуацию деструкции симметрии data-driven-коммуникации возможно метафорически обозначить, по аналогии с классическим (Foucault, 1975) и цифровым паноптиконом (Han, 2015), как «цифровой датифицированный паноптикон».

\section{Цифровая экономика: коммуникативные особенности
и модели}

Тотальная цифровизация процессов в информационном пространстве послужила основанием формирования цифровой экономики (digital economics). В узком смысле ЦЭ включает применяемые в экономике математические методы и модели, основанные на цифровом формате представления информации (Козырев, 2018). В широком смысле цифровая экономика (Negroponte, 1996; Tapscott, 1997) характеризуется цифровизацией процессов и инфраструктуры в бизнесе (оборудование, программное обеспечение, связь, человеческий капитал ит.д.), гиперсвязанностью (взаимодействием людей, организаций и машин благодаря Интернету и интернету вещей, мобильным технологиям) и т.д. (Mesenbourg, 2001).

Количество трактовок и концепций цифровой экономики увеличивается (Бухт, Хикс, 2018; Головенчик, 2019 (а, б); Купчишина, 2018). Однако исследователи в первую очередь изучают сферу ИКТ, в частности ЦЭ как часть экономики, которая представлена компаниями, работающими преимущественно с цифровыми технологиями и бизнес-модель которых основана на циф- 
ровых продуктах или услугах, состоит из цифрового сектора в сумме с перспективными цифровыми и платформенными услугами (Бухт, Хикс, 2018).

С точки зрения социальной коммуникации в ЦЭ формируются новые параметры взаимодействия. Согласно исследованию компании Deloitte (2019), это, в частности, организация труда, независимая от пространственных и временных границ (в том числе распределенная и судаленным доступом), с новыми требованиями к креативности; с уникальными условиями прямого, персонализированного взаимодействия с целевыми аудиториями - беспроводного, омниканального, для получения людьми особого пользовательского опыта; а также модели оперативного создания бизнесом цифровых экосистем для сверхбыстрой работы с данными 12 .

В 2019 г. в докладе о стратегиях развития человеческого капитала в так называемой экономике 4.0 Всемирного экономического форума (World Economic Forum) в Давосе отмечены императивы для рабочей силы будущего, в частности развитие новых лидерских возможностей и опыта сотрудников, интеграция технологий в управлении человеческими ресурсами ${ }^{13}$.

Датификация в обществе провоцирует формирование новых групп, которые некоторые исследователи именует даже дата-классами (Manovich, 2015). (С нашей точки зрения, это не вполне корректно, поскольку суть экономических и социальных взаимодействий, механизмы получения добавленной стоимости пока не вполне обоснованы.) Согласно Л. Мановичу, появляются дата-классы создателей данных (рядовые интернет-пользователи, чьи данные используют иные классы в своих целях); держатели «цифровых активов», обладающие возможностями и компетенциями сбора цифровых данных (осуществляющие распределение собранных массивов данных на основе собст- венных интересов); акторы, обладающие компетенциями анализа больших данных и имеющие доступ к цифровым массивам (использующие их для воздействия на представителей первого дата-класса). Выделяют и четвертый дата-класс - элитарную группу, способную контролировать остальные дата-классы в своих интересах (Володенков, 2018).

Итак, в актуальной модели цифровой экономики с точки зрения взаимодействия базисного субъекта и аудитории необходимо обеспечение свободного прямого доступа общественности, рядовых граждан ко всем цифровым процессам и к реализации коннективности для получения пользователями нового персонального опыта, в организациях необходимы навыки нового лидерства, основанного на технологиях. То есть коммуникация должна быть неиерархической, горизонтальной. Однако растущая человекоцентричность (точнее, юзер-центричность) в условиях датификации парадоксально провоцирует развитие цифрового дата-колониализма (Couldry, Mejias, 2019). Таким образом, модель коммуникации цифровой датифицированной экономики возможно описать как вертикальную иерархическую (гетерархическую), несимметричную.

\section{Коммуникация в квадроспирали российской цифровой экономики}

Российская Федерация по показателям цифровой экономики пока не входит в число стран-лидеров ${ }^{14}$. Однако, по мнению экспертов компании McKinsey, РФ является цифровой страной, в которой строится экосистема, основанная на управлении данными (McKinsey Global Institute, 2017), в первую очередь благодаря патерналистской поддержке цифровой экономики государством.

Отечественная цифровая экономика, согласно основным нормативным документам, в частности «Стратегии разви- 
тия информационного общества в Российской Федерации на 2017-2030 годы»,это хозяйственная деятельность, в которой ключевым фактором производства являются данные в цифровом виде, обработка больших объемов и использование результатов анализа которых по сравнению с традиционными формами хозяйствования позволяют существенно повысить эффективность различных видов производства, технологий, оборудования, хранения, продажи, доставки товаров и услуг ${ }^{15}$.

Согласно программе «Цифровая экономика Российской Федерации», ЦЭ должна способствовать формированию информационного пространства с учетом потребностей граждан и общества в получении качественных и достоверных сведений, развитию информационной инфраструктуры страны, созданию и применению российских информационно-телекоммуникационных технологий, а также формированию новой технологической основы для социальной и экономической сферы ${ }^{16}$.

Государство создает финансовые, технические и технологические предпосылки для создания информационных систем (Министерство цифрового развития, связи и массовых коммуникаций (до 2018 г. - Министерство связи и массовых коммуникаций); общественные институты поддержки - АНО «Цифровая экономика», принят одноименный национальный проект, а в 2019 г. - «Национальная стратегия развития искусственного интелелекта на период до 2030 г.»).

По данным Российской ассоциации электронных коммуникаций (РАЭК), вклад цифровой экономики в общую экономику России оценивался в 2,1\% ВВП (вклад мобильной экономики - 3,8\% ВВП; 4,35 трлн руб. в 2017 г.). В 2019 г. объем экономики Рунета составил 4,7 трлн руб., что превисило показатели 2018 г. на 20\%, чем в 2018 г. ${ }^{17}$
Согласно экспертам РАЭК, национальная цифровая экономика - это система, в которой добавленную стоимость создают ИКТ. В цифровой системе три уровня: рынки и секторы экономики, платформы и технологии, а также среда, куда включают нормативное регулирование, информационную инфраструктуру, безопасность персонала и информации. Объем хабов экономики Рунета в 2019 г. также вырос, например в рекламе и маркетинге до 330 млрд руб. 18

На нынешнем этапе преимущественными для развития ЦЭ названы задачи создания инфраструктуры - приоритет отдан ИКТ, телекоммуникациям и законодательству. То есть в реализации программ обязательно участие государства и большого бизнеса, в первую очередь в сфере информационных технологий, а также научного сообщества ${ }^{19}$. Бизнес отвечает на запрос государства, включаясь в процессы датификации (Медовников (ред.), 2018). Реализуются программы подготовки кадров для цифровой эконох мики. В частности, в рамках одноименного национального проекта к 2024 г. будет выстроена система образования, которая позволит выявлять и поддерживать таланты в области математики и информатики, готовить высококвалифицированные кадрысключевыми компетенциями в сфере экономики; 10 млн россиян должны пройти обучение по онлайн-программам развития цифровой грамотности 20.

При этом несмотря на то, что проблемы обеспечения прав человека в цифровом мире, сохранности цифровых данных пользователя, обеспечения доверия граждан к цифровой среде названы в числе вызовов цифровизации для России ${ }^{21}$, программы вовлечения рядовых граждан в ЦЭ, соответствующие масштабу проекта ЦЭ, не анонсированы, инициативы цифровизации для россиян пока чаще имеют безальтернативный характер 22. 
Отметим, что аудитория Рунета в 2019 г., по данным РАЭК, составляет 95,9 млн пользователей, проникновение Интернета $78,1 \%$, мобильная аудитория выросла до 85,2 млн человек 23 , то есть технологические предпосылки доступа и интернетвзаимодействия вполне сформированы. Индекс цифровой грамотности, согласно данным Российского центра интернеттехнологий (РОЦИТ), растет (в частности, индекс в 2017 г. составил 5,99, субиндекс цифрового потребления - 5,35, субиндекс цифровых компетенций - 6,4824).

Таким образом, российская модель цифровой экономики - квадроспираль ЦЭ-в соответствии с нормативными документам может быть описана как многосторонняя симметричная. Однако на первом инфраструктурном этапе ее формирования (с 2017 г. по настоящее время) рядовые граждане как нормативные акторы и основная массовая целевая аудитория пока номинально не включены во взаимодействие в таких же форматах и объемах, как это декларируется, например, во взаимодействии государства и бизнеса, то есть квадроспираль ЦЭ функционирует асимметрично.

\section{Связи с общественностью как "стратегия доверия" в цифровой экономике}

Реализация отечественной модели цифровой экономики, несмотря на коммуникативные парадоксы датификации и асимметрию модели первого инфраструктурного этапа, обусловливает необходимость нормативного участия всех акторов квадроспирали. Эффективное взаимодействие определяет значимость доверия и потенциальную необходимость участия специалистов по связям с общественностью в этих процессах.

Согласно оценке российских исследователей (Федюнин, Шилина, 2019) и экспертов (в рамках данного исследования,
2019), для привлечения в цифровую экономику профессионалов пиара существует ряд объективных предпосылок. В частности, внедрение любых инновационных программ создает условия для турбулентности, неопределенности, а значит, повышает уровень недоверия в экономике и обществе, то есть востребованы антикризисные коммуникации по восстановлению и формированию доверия.

Также в датифицированном информационном пространстве коммуникация, начиная с экономической, становится коммуникацией когнитивной, то есть весьма сложной для аудитории, что также обусловливает необходимость ее сопровождения профессиональными коммуникантами. Все большее количество форматов взаимодействия в цифровой датифицированной экономике являются человекомашинными, гибридными в максимально широком толковании, что также требует адаптации к ней аудитории. И, наконец, россияне в новейшей истории включены в модернизационные процессы как базисные субъекты впервые, и отсутствие опыта равноправной симметричной коммуникации в экономике и обществе также требует особого внимания.

Каковы базовые характеристики отечественных связей с общественностью как стратегической коммуникации в цифровой экономике?

Проведем компаративный анализ основных актуальных характеристик субъект-объектного взаимодействия базисного субъекта с целевой аудиторией (общественностью) в моделях маркетинга, связей с общественностью и стратегической коммуникации с учетом российской специфики.

Моделирование в маркетинге 25 с точки зрения изучения базовых параметров взаимодействия продавца и покупателя (B2C, business-to-client) особенно активно применяется в последнее время, в связи 
с развитием персонализированного подхода к клиенту (Татаринов, 2019).

Линейка маркетинговых моделей расширяется за счет все более клиенто-, а затем и человекоцентричных: от классических моделей продвижения продукта26 до модели взаимоотношений (Голубева, 2017, 2019; Соловьев (ред.), 2010), в которой коммуникация с целевыми аудиториями определяет гибкие трансформации брендов, особенно с учетом интернетизации процессов (Багиев, 2011; Скоробогатых, Сидорчук, Андреева (ред.), 2020). Персонализированный маркетинг, основанный на применении интернет-технологий, обеспечивает двустороннее субъект-субъектное взаимодействие с аудиторией (Данько, Китова, 2013; Юлдашева, Окольнишникова, 2012). Модель маркетинга вовлечения включает в разработку и продвижение товара непосредственно потребителя (Випперфюрст, 2007), которому прививается новая культура потребления (Юлдашева, 2006) и предлагаются возможности образования (например, модель 5E27). Удовлетворение потребителей становится параметром для оценки эффективности коммуникации в моделях лояльности 28 (Цветкова (ред.), 2017). Актуальные модели маркетинга строятся на основе постоянного взаимодействия (например, модель 5E29), эмоциональной привязанности (напр., модель $4 \mathrm{E}^{30}$ ) и общих ценностей (напр., 7531).

В условиях цифровизации на смену концепциям традиционного физического управления приходит цифровой виртуальный маркетинг, который определяет дополнение классической модели 4Р и модели маркетинга в Интернете $4 S^{32}$ такими характеристиками, как персонализация, а также конфиденциальность, безопасность, работа с потребителями и сообществами, особенно с цифровыми потребителями в системе маркетинга 4.0. (Скоробогатых, Мусатова, 2018; 2019). Персона- лизация как основа функционирования современной модели В2С-маркетинга в условиях датификации становится все более эффективной, благодаря точной таргетированности и интерактивности (Вирин, 2010). Исследователи фиксируют появление data-driven-маркетинга (Скоробогатых, Невоструев, Мусатова, Ивашкова, 2018).

Таким образом, классическая вертикальная иерархическая модель маркетинга В2С в современных условиях трансформируется во многом благодаря цифровизации: целеполагание изменяется в пользу формирования общих ценностей, стратегически важным признано персонализированное, интерактивное и точно таргетированное взаимодействие с целевой аудиторией, а также формирование лояльности, то есть традиционный вертикальный вектор модели маркетинговой коммуникации сменяется на горизонтальный, для точно таргетированной персонализированной коммуникации с аудиторией.

Каковы особенности актуальных маркетинговых моделей в Российской Федерации в условиях цифровой экономики? В 2019 г. индустриальные эксперты подтвердили тенденции цифровизации и датификации (когда большие данные становятся "зеркалом продаж»), а также персонализации (когда таргетирование происходит по людям, а не по рекламным ID или cookies. По мнению М. Вощинского (CEO, Dentsu Aegis Network Russia), «взаимодействовать с потребителем стало очень сложно: он все время куда-то ускользает, контакт с рекламой падает, лояльность к брендам меняется, появляются новые сегменты потребителей, которые надо захватывать. Данных на рынке очень много, и большинству игроков пока не ясно, как с ними работать, но при этом все четко осознают, что за big data будущее построения коммуникации и оценки бизнесрезультатов» 33 . 
Согласно ежегодному глобальному исследованию Getting Media Right от компании Kantar Millward Brown, в 2019 г. российские маркетологи более радикально настроены по поводу сокращения вложений в традиционные каналы коммуникации, такие как пресса и наружная реклама в пользу цифровых каналов (реже испытывают проблемы сокращения бюджетов по сравнению с зарубежными коллегами на других рынках). Технологии внедряются активно (например, программатик), высоко качество таргетирования, однако в России, как и за рубежом, основными показателями эффективности для всех каналов коммуникации по-прежнему остаются количественные показатели - охват и частота (причем эти метрики используются в том числе для оценки многоканальных рекламных кампаний и рекламы на различных типах устройств - десктопах и мобильных телефонах) 34 .

Таким образом, современные модели российского маркетинга, все более цифровизируются и датифицируются, однако их параметры пока точно не определены, а показатели эффективности остаются количественными.

Интегрированные маркетинговые коммуникации (ИМК) - становятся все менее маркетинговыми, все более не клиенто-, а человекоориентированными. Согласно российским исследованиям, особенность интегрированных коммуникаций - согласованные стратегии и ключевые сообщения на всех каналах, а также включение в коммуникационные кампании внутренних целевых аудиторий, постоянные исследования на всех этапах для оптимизации коммуникации ${ }^{35}$. То есть эволюция интеграции также все более ориентирована на рядового ее участника, который должен стать субъектом коммуникации.

Моделирование в связях с общественностью не столь обширно, многопланово и динамично, как в теории маркетинга.
Учеными описана лишь одна базовая линейка моделей (еще в 1980 гг.), включающая рекламную (протопиар), информационную, двустороннюю асимметричную модели (Grunig, Hunt, 1984). Эти матрицы соответствовали определенным историческим экономико-социальным периодам американского пиара прошлого века и отражали вектор взаимодействия между заказчиком и аудиторией и косвенно обозначали функции пиар-специалистов. Согласно Грюнигу и Ханту, наиболее эффективной в СО принято считать двустороннюю симметричную модель коммуникации, которая фиксирует паритетное взаимодействие субъекта и объекта.

Цифровые виртуальные модели связей с общественностью в этой исторической офлайн-линейке, по понятным причинам, не были рассмотрены. В Интернете же модели из данной классической типологии не вполне применимы. Так, наиболее прогрессивная классическая офлайнмодель двусторонней коммуникации не соответствует процессам взаимодействия в Сети, поскольку не учитывает новых прямых и опосредованных базисных цифровых субъектов - людей (реальных) и буквально цифровых виртуальных субъектов (программы, нейросети, подключенные «вещи» и т.д.). Цифровая, в том числе интернет-коммуникация, реализуется в особой виртуальной среде, где эти акторы выступают в качестве специфических вполне автономных субъектов. Целевая аудитория, рядовой пользователь, коммуницируя в Сети, из объекта трансформируется в специфического субъекта, точнее объекта-субъекта, просьюмера - создателя и потребителя информации и коммуникации, сообщений и ресурсов. Данная цифровая модель описана как пятая фрактальная модель, по типологии Грюнига-Ханта (Шилина, 2012).

В условиях датификации предложенный фрактальный принцип описания модели 
коммуникации связей с общественностью в Интернете все менее применим, т.к. базисные цифровые субъекты обладают все большим количеством проприетарных технологий, данных и результатов их анализа; в итоге во взаимодействии всех уровней в физическом, цифровом, гибридном пространстве баланс смещается в сторону ЦБС. Таким образом, коммуникация оказывается не только все более асимметричной, но и все более жестко структурированной, то есть все менее фрактальной - возможно, даже афрактальной.

В 2019 г. отечественные связи с общественностью продолжают функционировать в маркетинговой парадигме: согласно индустриальным исследованиям агентства Buman Media, маркетинговые коммуникации являются вторыми по востребованности в арсенале пиар-специалистов. При этом расширяется интернет-инструментарий, в первую очередь за счет социальных сетей (23\%), корпоративного блогинга (4\%), онлайн-СМИ (18\%), электронной рассылки (6\%), мессенджеров (5\%) ${ }^{36}$, популярно взаимодействие с блогерами и лидерами мнений (11\%).

Несмотря на превалирование маркетинговых функций и инструментов, исследователи Ассоциации коммуникационных агентств России (АКАР) выявили стратегические направления в корпоративной коммуникации - например, внутренние коммуникации, связи с инвесторами (investor relations, IR), связи с органами власти (government relations, GR), финансовые коммуникации, брендинг территорий ${ }^{37}$.

Таким образом, российскую модель data-driven-коммуникации в связях с общественностью возможно описать как гибридную, многостороннюю, асимметричную. Расширение состава (и увеличение количества) нормативных цифровых субъектов модели - прямых (программы, подключенные «вещи») и непрямых базисных (владельцы ИКТ, платформ, данных, «ве- щей»), определяет большую асимметрию и афрактальность ее функционирования.

Стратегии и стратегические коммуникации несмотря на растущую экономическую и социальную турбулентность все более востребованы в связях с общественностью, согласно ведущим зарубежным исследователям (van Ruler, Korver, 2019).

Стратегическая коммуникация как актуальная концепция формируется на стыке теорий и практик маркетинга и связей с общественностью в последние десятилетия. Предпосылками создания концепции стратегических коммуникаций, в первую очередь в корпоративной сфере, стала цифровизация, спровоцировавшая перманентный рост многообразия, дифференциации и фрагментации целевых аудиторий и каналов коммуникации. В концепции стратегических коммуникаций зафиксировано, что все направления корпоративной коммуникации - связи с общественностью, маркетинг и др. - обретают общие цели, стратегии их достижения становятся сходными (Hallahan, Holtzhausen, van Ruler, Verčič et al., 2007).

Сегодня в отечественном академическом дискурсе несмотря на различие подходов и трактовок «общим является понимание стратегических коммуникаций как предельно широкой по своему охвату деятельности, связанной с достижением стратегических целей, необходимостью синхронизации действий организации для решения поставленных задач, продвижением или изменением культурных (идеологических) ценностей в сознании целевых аудиторий, улучшением имиджа государства на международной арене» (Богданов, 2017: 136).

Весьма общие критерии и отсутствие точного понимания и непротиворечивого определения сущности стратегических коммуникаций отражают отсутствие систематизированных практик СК и научной рефлексии в России. 
Сущность стратегической коммуникации, согласно классическому определению, продвигать миссию организации через коммуникацию (Hallahan, Holtzhausen, van Ruler, Verčič et al., 2007: 3). Именно цель, а не какие-либо свойства коммуникации, по меткому замечанию известного исследователя из Нидерландов Беттеке ван Рулер (2018), определяет принадлежность коммуникации к стратегической.

Характеристики стратегических коммуникаций тем не менее в целом определены и во многом совпадают с особенностями актуального человекоцентричного маркетинга, интегрированных коммуникаций, связей с общественностью. В частности, все форматы коммуникации сфокусированы на интересах и потребностях аудитории; коммуникации, решения, действия и ключевые сообщения выстроены и координируются в едином ключе для достижения стратегических целей; основные сообщения адаптированы ко многим и диверсифицированным аудиториям и каналам; коммуникации реализуются непрерывно и длительно 38 .

Существенным для стратегической коммуникации является то, как организация функционирует в качестве социального актора для продвижения своей миссии, как представляют и продвигают себя ее руководители, сотрудники и профессиональные коммуникаторы (Hallahan, Holtzhausen, van Ruler, Verčič et al., 2007: 7). Модель стратегической коммуникации исходя из приведенного выше классического определения включает и внутренние аудитории, которые не упомянуты специально.

Отметим, что стратегическая коммуникация, согласно Ньюманну, становится прямым диалогом (Neumann, 2008), то есть реализуется по двусторонней симметричной модели, и нельзя назвать стратегической коммуникацию по односторонней модели, как предлагалось некоторыми теоретиками (Paul, 2011).
Сегодня исследователи пересматривают концепцию стратегической коммуникации как деятельности по сопровождению стратегии организации только во внешней сфере, переходя к более современному пониманию коммуникации как многосторонней симметричной (не обязательно двусторонней). СК становится неотъемлемой составляющей формирования, обсуждения, презентации, реализации и оптимизации стратегии субъекта коммуникации во внешней и внутренней аудиториях. В частности, стратегическая коммуникация определяется как процесс «гибкого управления, в котором основное внимание уделяется (информационнокоммуникационной) подпитке аудиторий, причем для построения и реализации стратегии в коммуникационном продукте смыслы представлены, согласованы, созданы или оптимизированы в процессе тестирования стратегических решений путем их непрерывного представления и обсуждения» (van Ruler, 2018: 379).

Цифровая модель стратегической коммуникации опосредована теми же технологиями, что маркетинговые и пиар-модели, это позволяет при условии выявленного сходства в целеполагании и функционировании, предположить сходные параметры функционирования моделей этих трех форматов коммуникации в Интернете в условиях датификации.

Датифицированные модели МК, СО, СК представляются новыми для практики и теории коммуникации, поскольку изменяется характер взаимодействия, состав субъектов: цифровые и гибридные акторы являются такими же автономными участниками коммуникации, как человек; непрямыми базисными субъектами становятся владельцы программ, данных, инфраструктуры.

Итак, анализ базовых моделей российского маркетинга, СО и модели стратегической коммуникации, предложенной ев- 
ропейскими исследователями (протомодели, на стадии становления), позволяет зафиксировать во взаимодействии субъекта и объекта коммуникации тенденцию интерактивной персонализации коммуникации, значимость формирования для базисного субъекта (в первую очередь корпорации) и ее аудиторий совместных ценностей.

Одной из базовых ценностей (и целей) маркетинга взаимоотношений, связей с общественностью и стратегической коммуникации и ключевых факторов функционирования цифровой экономики является доверие.

Изучение доверия как базового элемента и функции институциональных связей с общественностью несмотря на очевидную коммуникативную сущность этого феномена носит фрагментарный характер даже у исследователей аксиологических характеристик пиара (Кужелева-Саган, 2011). Цифровое доверие одними из первых проанализировали томские ученые, зафиксировав возможности формирования гудвилла в интерактивном дизайне как инструменте пиара (Kuzheleva-Sagan, Suchkova, 2016).

Каковы основные коммуникативные особенности данного феномена в гибридной коммуникации российской цифровой экономики? Доверие как эмоциональное явление и процесс становится все более операциональным (Веселов (ред.), 2004; Коулман, 2004; Luhmann, 1979). Классическая модель формирования доверия это двусторонняя симметричная модель коммуникации между объектом и субъектом. Процесс формирования доверия обусловлен первоначальным импульсом, который зависит от внешних характеристик объекта потенциального доверия, его репутации (Штомпка, 2012), а также от контекста, статуса коммуникантов и т.д. Схематично этот процесс возможно описать следующим образом: первый актор, ока- зывая доверие второму, делегирует ему некие полномочия; второй актор должен оправдать доверие, приняв на себя ответственность за выполнение возложенных на него обязательств. Как правило, в итоге подобной успешной - непременно двусторонней симметричной - коммуникации выигрывают обе стороны (Коулман, 2004).

Доверие в процессе взаимодействия человека и техники в последнее время становится отдельным направлением исследований. В самом общем виде оно описывается на двух уровнях: как доверие непосредственно к техническому объекту и доверие к создателю этого объекта (Штомпка, 2012).

В цифровой датифицированной гибридной коммуникации взаимодействие человека/аудитории и техники реализуется по более сложной многоступенчатой матрице. В виртуальном или гибридном пространстве человек интерактивно взаимодействует напрямую с программой, подключенной «вещью» ит.д.; коммуникация с ним виртуальной среды постоянно изменяется, адаптируясь под его запросы. При этом в процессе опосредованно участвуют цифровые базисные субъекты различного уровня: на первом уровне это - программисты, владельцы программного обеспечения, представители иных технологических профессий, которые обеспечивают возможность прямой коммуникации; на втором - владельцы площадки, заказчики проектов и т.д. Опосредованными цифровыми базисными субъектами являются владельцы данных. Возможно уровневое деление на реальных и виртуальных коммуникантов и т.д. То есть цифровое доверие техническому объекту носит многофакторный и многоуровневый характер.

Цифровые субъекты всех уровней и их целеполагание, интересы, стратегии в большинстве случаев специально не анонсируются аудитории и ей неизвестны. То есть модель доверия в цифровой дати- 
фицированной коммуникации асимметрична изначально. С увеличением числа цифровых базисных субъектов асимметрия нарастает.

Для обеспечения доверия аудитории цифровым дата-технологиям и акторам возникает особая необходимость в ее открытости и прозрачности. Это также свидетельствует в пользу участия связей с общественностью в процессах цифровизации и датификации.

В России особенности доверия в обществе противоречивы и дуалистичны, невысокое доверие к окружающим сосуществует с высоким доверием к главе государства, церкви, армии (Гудков, 2012).

Отметим, что в квадроспирали ЦЭ «государство-бизнес-наука-граждане» исследователи выявили максимальное доверие к государству, научному сообществу, ожидаемо низкое - к бизнесу, при невысоком уровне знакомства граждан с программой развития цифровой экономики (около 20\% респондентов) (Шилина, Вартанов, 2019).

Таким образом, стратегические связи с общественностью в парадигме цифровой экономики для достижения доверия между всеми акторами должны функционировать по многосторонней симметричной модели. Выявленная на теоретическом уровне схожесть актуальных матриц маркетинговой, пиар- и стратегической коммуникации по целеполаганию, ценностям, функциям позволяет предположить, что возможно формирование интегрированной/конвергентной модели на основе имеющихся.

При этом растущая опосредованность этих форматов профессиональной социальной коммуникации Интернетом и датифицированными технологиями ведет к априорной деструкции симметрии модели коммуникации, а также к априорной нетранспарентости и деструкции основ доверия.
Российские практики data-driven-маркетинга и СО находятся на стадии становления, однако интернетизация и датификация становятся растущим трендом, вызывающим энтузиазм представителей индустрии, а значит, и рост парадоксальных data-driven-практик.

Эксперты, по результатам опроса и форсайт-сессии, согласно картам восприятия обеих групп (исследователей и практиков), определяют состояние индустрии в равной степени как классическое маркетинговое (50\%), так и транзитивное (60\%). Никто не обозначил стратегические функции СО как доминирующие. Проникновение датификации в индустрию оценено как в достаточной степени высокое (40\% респондентов). Практики включенности в процессы реализации программ цифровой экономики на уровне индустрии и общественности как широкой целевой аудитории отметили лишь некоторые респонденты (20/30\%). Цифровой датифицированный институциональный разрыв как проблему для развития индустрии в итоге признало вероятным более половины экспертов (60\%). Особенности датифицированной цифровой коммуникации и применение data-driven-технологий в индустрии воспринимается более позитивно практиками, чем теоретиками; перспективы влияния датификации на институализацию связей с общественностью оценены как незначительные. Переход СО от классического маркетинга к стратегическим функциям считает вероятным около трети респондентов (30\%) и не ранее, чем через десять лет.

В условиях расширяющейся цифровизации и датификации предполагается, что коммуникационная модель российских СО, как и модели маркетинговой и стратегической коммуникации, трансформируется в омниканальную, однако, как предполагают все респонденты, только в долгосрочной перспективе. 


\section{Заключение}

Российская цифровая экономика и ее модель квадроспирали (государство-бизнес-наука-общественность) демонстрируют особый формат цифровой data-drivenконвергенции: благодаря нормативному включению граждан как субъектов зафиксирована национальная матрица концепции дата-капитализма и новый подуровень дата-колониализма.

В подобной парадигме цифровой экономики, где широкая общественность становится нормативным субъектом, отечественные связи с общественностью получают основания для перехода в статус не маркетинговой, но стратегической коммуникации. При этом теоретические и практические предпосылки диффузии базовых параметров моделей маркетинговой, пиар- и стратегической коммуникации, в первую очередь в цифровом формате, и деструкции как классических функций, так и классической же оппозиции МК, СО и СК, позволяют предположить возможности, во-первых, бесшовности подобного перехода и, во-вторых, появления новой модели профессиональной социальной коммуникации - омнипрофессиональной.

Однако зафиксированные характеристики цифровизации и датификации провоцируют деструкцию симметрии коммуникации как наиболее эффективной парадигмы профессионального взаимодействия. В частности, цифровизация и датификация провоцируюттрансформации классической структуры и субъектности акторов связей с общественностью: изменяется статус аудитории, просьюмеры становятся новыми базисными субъектами; появляются априорные (в цифровой экономике - нормативные) цифровые базисные субъекты - владельцы технологий, ресурсов, данных и т.д., а также гибридные цифровые субъекты. Доверие в цифровой и data-driven-парадигме реализуется также по асимметричной модели. Контекст коммуникации становится все более нетранспарентным.

Датифицированный цифровой разрыв делает любое развитие и расширение коммуникационных потоков киберопасным и служит основанием для институционального датифицированного цифрового разрыва в связях с общественностью.

В условиях первого этапа реализации программ цифровой экономики (с 2017 г. по настоящее время) зафиксирована асимметрия коммуникативной модели квадроспирали ЦЭ (и дата-капитализма/дата -колониализма как такового).

В итоге обозначенные выше параметры деструкции постулатов (и практик) связей с общественностью не только не способствуют повышению их институционального статуса, но де факто противоречат самой идее институционализации, которая подразумевает, в частности, обеспечение многосторонней симметричной коммуникации (Grunig, Hunt, 1984), замену спонтанного и экспериментального поведения на поведение регулированное, ожидаемое, предсказуемое (Шишкина, 1999).

Таким образом, выдвинутая гипотеза о том, что в условиях цифровой экономики предполагается трансформация модели отечественных связей с общественностью из маркетинговой в стратегическую и это повысит институциональный статус СО, опровергнута. Во-первых, размывание границ между актуальным маркетингом, СО и стратегической коммуникацией означает отсутствие жесткой оппозиции между ними - и, следовательно, возможность мягкой бесшовной трансформации (и даже формирование омнипрофессиональной модели социальной коммуникации). Во-вторых, однако, это не означает автоматическое повышение институционального статуса СО как стратегической коммуникации. Выявленная в результате исследования деструкция симметрии коммуникации как базового ус- 
ловия эффективности взаимодействия на всех уровнях (ЦЭ, квадроспираль ЦЭ, интернет- и data-driven-коммуникация, MK, СО, СК, цифровое доверие) определяет деструкцию классических и новых постулатов теорий и практик коммуникации, опосредованных цифровыми датифицированными технологиями. (Более того, декларируемая человекоцентричность профессиональной коммуникации будет лишь усиливать зафиксированную в исследовании ситуацию цифрового датифицированного паноптикона и профессионального разрыва.)
Несмотря на парадоксальность полученных результатов, формирование эффективной коммуникации в парадигме ЦЭ, по мнению экспертов, вполне вероятно в долгосрочной перспективе, в частности потому, что проекты цифровой экономики в России реализуются по государственной патерналистской модели, предполагающей приоритет общественных ценностей.

Появление нового эмпирического материала по данной теме позволит подтвердить - или вновь опровергнуть - гипотезу и результаты данного теоретического исследования.

\section{Примечания}

1 Программа «Цифровая экономика Российской Федерации», утвержденная распоряжением Правительства Российской Федерации от 28 июля 2017 г. № 1632-р. Режим доступа: http://government.ru/docs/all/112831/ (дата обращения: 10.10.2019).

2 G20 Ministerial Statement on Trade and Digital Economy (2019). Режим доступа: http:// www.g20.utoronto.ca/2019/2019-g20-trade.html (дата обращения: 10.10.2019).

3 Программа «Цифровая экономика Российской Федерации». 2017. С. 5.

4 IDC Annual Report. 2017. Режим доступа: https://www.idc.org/pdf/17_ici_annual.pdf (дата обращения: 10.09.2018).

5 Исследование Buman Media и HeadHunter: чем живет рынок PR-коммуникаций России в 2019 году. Режим доступа: https://www.cossa.ru/news/238217/ (дата обращения: 10.10.2019).

6 Национальная стратегия развития искусственного интеллекта на период до 2030 года. Режим доступа: https://www.garant.ru/products/ipo/prime/doc/72738946/ (дата обращения: 10.10.2019).

7 Владимирова Н. Маркетинг-2019: экспертный взгляд на рынок, или Что нужно держать в фокусе в следующем году вашему директору по маркетингу // Inc. Russia. Режим доступа: https://incrussia.ru/understand/marketing-2019-ekspertnyj-vzglyadna-rynok-ili-chto-nuzhno-derzhat-v-fokuse-v-sleduyushhem-godu-vashemudirektoru-po-marketingu/ (дата обращения: 10.10.2019).

8 Digital Economy and Society Index. Режим доступа: https://ес.europa.eu/digitalsingle-market/en/desi (дата обращения: 10.10.2019).

9 Аудитория Рунета выросла на 7\% за три года. Режим доступа: https://mediascope. net/news/1035826/ (дата обращения: 10.10.2019).

10 Рунет подвел итоги года: объем экономики Рунета составил 4,7 трлн рублей / РАЭК, 2019. Дек., 16. Режим доступа: https://raec.ru/live/raec-news/11400/ 
${ }^{11}$ Greenfield P. (2018) The Cambridge Analytica files: the story so far. The Guardian, March 28. Режим доступа: https://www.theguardian.com/news/2018/mar/26/thecambridge-analytica-files-the-story-so-far (дата обращения: 10.05.2019).

12 What is digital economy? Deloitte, 2019. Режим доступа: https://www2.deloitte. com/mt/en/pages/technology/articles/mt-what-is-digital-economy.html (дата обращения: 10.10.2019).

13 HR4.0: Shaping People Strategies in the Fourth Industrial Revolution. Режим доступа: https://www.weforum.org/reports/hr4-0-shaping-people-strategies-in-the-fourthindustrial-revolution (дата обращения: 10.10.2019).

${ }^{14}$ Networked Readiness Index. Режим доступа: https://reports.weforum.org/globalinformation-technology-report-2016/networked-readiness-index/?doing_wp_cron= 1577607861.4106650352478027343750 (дата обращения: 10.10.2019).

15 «Стратегия развития информационного общества в Российской Федерации на 2017-2030 годы», утвержденная Указом Президента РФ от 9 мая 2017 г. № 2032. Режим доступа: http://kremlin.ru/acts/bank/41919 (дата обращения: 10.10.2019).

16 Программа «Цифровая экономика Российской Федерации».

17 Рунет подвел итоги года: объем экономики Рунета составил 4,7 трлн рублей.

18 См. также хабы: Инфраструктура - 130 млрд руб., Электронная коммерция 2850 млрд руб., Платежные услуги - 1350 млрд руб., Цифровой контент 115 млрд руб // Рунет подвел итоги года: объем экономики Рунета составил 4,7 трлн рублей.

19 Программа «Цифровая экономика Российской Федерации».

20 Кадры для цифровой экономики. 2019. Июнь, 24. Режим доступа: https://digital. gov.ru/ru/activity/directions/866/ (дата обращения: 10.12.2019).

21 Программа «Цифровая экономика Российской Федерации».

22 Корня А. Суд разрешил властям следить за людьми через системы распознавания лиц. Опубликована мотивировочная часть решения по иску о защите персональных данных // Ведомости. 2019. Ноябрь, 25. Режим доступа: https://www. vedomosti.ru/technology/articles/2019/11/26/817135-vlasti-sledit (дата обращения: 30.12.2019).

23 Рунет подвел итоги года: объем экономики Рунета составил 4,7 трлн рублей.

24 Индекс цифровой грамотности. 2017. Режим доступа: https://rocit.ru/uploads/76 9c4df4bc6f0bd6ab0fbe57a056e769b8be6bcf.pdf?t=1517847097 (дата обращения: 10.12.2019).

25 В маркетинге традиционно применяют множество различных моделей для разных отраслей, сфер, компаний, уровней коммуникации - например, товарных, производственных, сбытовых, предметных, информационных, математических и т.д.

26 Например, от моделей 4Р и 5Р (продукт/product, цена/price, продвижение/promotion, место/place, а также positioning - процессы позиционирования компании на рынке), к 7Р и ориентированной на потребителя модели 4С (потребитель/ consumer, стоимость для ЦА/cost, удобство для ЦА/convenience, коммуникации с ЦА/communication).

27 Модель $5 E$ описывает необходимость обучения клиентов (education), улучшения их жизни (elevation), получения клиентом удовлетворения от взаимных 
контактов (entertainment), а также постоянные исследования клиентской базы (exploration) и оценку эффективности на основе этих параметров.

28 Модель лояльности 4L создана на основе стандартов измерения удовлетворенности потребителей ISO 9001:2000B, отражает формирование лояльности (loyalty) четырех целевых групп: потребителей продукта как адресатов программ лояльности и как лиц, влияющих на лояльность других; сотрудников компании; лидеров мнений; конкурентов.

29 См. модель 5E.

30 Модель 4E нацелена на эмоциональную вовлеченность: формирование привязанности, преданности потребителей путем воздействия на их эмоции и включает такие параметры, как этика (ethics), эстетика (esthetics), эмоции (emotions), преданность (eternities).

31 Модель 7S включает структуру (structure), системы (systems), стиль коммуникации (style), персонал (staff), навыки (skills), стратегию (strategy), и общие ценности субъекта и объекта взаимодействия.

32 В модели маркетинга в Интернете 4S (масштаб/scope, сайт/site, синергия/sinergy, системa/system) важны интеграция виртуальной и физической среды, маркетинговых и организационных процессов в связи с быстро изменяющимися условиями инфосферы, а также стратегическая роль маркетологов.

33 Материалы конференции Advertising Imaginarium. Режим доступа: https://adindex. ru/specprojects/city-2019/ (дата обращения: 10.12.2019).

34 Скопинцева В., Иванова Т., Лебедев К. Главные вызовы российской маркетинговой индустрии // Adindex.ru. 2019. Дек., 19. Режим доступа: https://adindex.ru/ publication/analitics/2019/12/19/278214.phtml (дата обращения: 30.12.2019).

35 Интегрированные коммуникации. НИУ ВШЭ, 2015. (Из архива М.Г. Шилиной.)

36 Поиск лучших инструментов, повышение статуса PR внутри компании и активная прокачка навыков - чем живет рынок PR России в 2019 году // Medium. 2019. Июль, 20. Режим доступа: https://medium.com/@bumanmedia/поиск-лучших-инструментов-повышение-статуса-рr-внутри-компании-и-активная-прокачка-навыков-чем-7el84d641425 (дата обращения: 10.12.2019).

37 Корпоративные коммуникации в России. Исследование АКАР. 2015. Режим доступа: https://corpmedia.ru/docs/corportivnye-communikacii-presentacyia.pdf

38 Goldman E. (2007) Strategic Communication: A Tool for Asymmetric Warfare. Small Wars Journal, October6. Режимдоступа: http://smallwarsjournal.com/blog/strategiccommunication-a-tool-for-asymmetric-warfare (дата обращения: 10.12.2019).

\section{Библиография}

Багиев Г.Л. Маркетинг взаимодействия. СПб: Астерион, 2011.

Богданов С.В. Стратегические коммуникации: концептуальные подходы и модели для государственного управления // Государственное управление. Электронный вестник. 2017. Вып. 61. С. 132-152. Режим доступа: http://e-journal.spa.msu.ru/ uploads/vestnik/2017/vipusk_61._aprel_2017_g./kommunikazionnii_menedjment_i_ strategitcheskaja_kommunikazija_v_gosudarstvennom_upravlenii/bogdanov.pdf (дата обращения: 10.11.2019). 
Буари Ф. Паблик рилейшнз, или Стратегия доверия / пер. с фр. М.: Инфра-М; Имидж-Контакт, 2001.

Бухт Р., Хикс Р. Определение, концепция и измерение цифровой экономики // Вестн. междунар. организац.: образование, наука, новая экономика. 2018. Т. 13. № 2. C. 143-172. DOI: 10.17323/1996-7845-2018-02-07

Быков И.А. Сетевая политическая коммуникация: Теория, практика и методы исследования: моногр. СПб: ФГБОУ ВПО «СПГУТД», 2013.

Випперфюрст А. Вовлечение в бренд: как заставить покупателя работать на компанию. М.: ИД «Коммерсант»; СПб: ИД «Питер», 2007.

Вирин Ф. Интернет-маркетинг. Полный сборник практических инструментов. М.: Эксмо, 2010.

Володенков C.B. Технологии Big Data в современных политических процессах: цифровые вызовы и угрозы // Вестн. Томск. гос. ун-та. Сер.: Философия. Социология. Политология. 2018. № 44. С. 205-212. DOI: 10.17223/1998863X/44/20

Володенков C.B. Big Data как инструмент воздействия на современный политический процесс: особенности, потенциал и акторы // Журнал политических исследований. 2019. Т. 3. № 1. С. 7-13.

Гавра Д.П. Категория стратегической коммуникации: современное состояние и базовые характеристики // Век информации. 2015. № 3 (4). С. 229-233.

Головенчик Г. (а) Теоретические подходы к определению понятия «цифровая экономика» // Наука и инновации. 2019. № 1. С. 54-59. DOI: 10.29235/1818-98572019-1-54-59

Головенчик Г. (б) Теоретические подходы к определению понятия «цифровая экономика» // Наука и инновации. 2019. № 2. С. 40-45. DOI: 10.29235/1818-98572019-2-40-45

Голубева М.А. Маркетинг взаимоотношений: учеб. пособие. Кострома: Изд-во Костромск. гос. ун-та, 2017.

Голубева М.А. Развитие концепции маркетинга взаимоотношений в условиях цифровой экономики // Изв. С.-Петербургск. гос. эконом. ун-та. 2019. № 5-1 (119). С. 118-123.

Гудков Л. Доверие в России // Общественное мнение. 2012. № 2 (112). С. 56-72.

Интернет-технологии в связях с общественностью: учеб. пособие / отв. ред. И.А. Быков, О.А. Филатова. СПб: Роза мира, 2010.

Данько Т.П., Китова О.В. Вопросы развития цифрового маркетинга // Проблемы современной экономики. Евразийск. междунар. научн.-аналит. журн. 2013. 3 (47). C. 261-265.

Козырев А.Н. Цифровая экономика и цифровизация в исторической ретроспективе // Цифровая экономика. 2018. № 1 (1). C. 5-19. DOI: 10.34706/DE-2018-01-01

Коулман Дж. С. Экономическая социология с точки зрения теории рационального выбора // Западная экономическая социология: хрестоматия современной классики / сост. и науч. ред. В.В. Радаев. М.: РОССПЭН, 2004. С. 35-44.

Купчишина Е.В. Эволюция концепций цифровой экономики как феномена неоэкономики // Государственное управление. Электронный вестник. 2018. № 68. С. 426-444. Режим доступа: http://e-journal.spa.msu.ru/uploads/vestnik/2018/vipusk_68._ijun_2018_g./ strategii_zifrovoi_ekonomiki/kupchishina.pdf

Кужелева-Саган И. Научное знание о связях с общественностью: философский анализ. М.: Либирком, 2011. 
Маркетинг взаимоотношений: учеб. пособие / под общ. ред. Б.А. Соловьева. М.: Изд-во РЭА им. Г. В. Плеханова, 2010.

Маркетинг: создание и донесение потребительской ценности: учеб. пособие/под ред. И.И. Скоробогатых, Р.Р. Сидорчука, С.Н. Андреева. М.: ИНФРА-М, 2020.

Минаев Д.В. Современная феноменология диджитал маркетинга // Маркетинг менеджмент в цифровой экономике. 2016. Т. 2. № 1. С. 21-50.

Окольнишникова И.Ю. Формирование и развитие маркетинговых коммуникаций в условиях индивидуализации потребительского спроса: автореф. дис. ... д-ра эконом. наук. СПб, 2011.

Скоробогатых И.И., Невоструев П.Ю., Мусатова Ж.Б., Ивашкова Н.И. Маркетинг в условиях развития цифровой экономики // Маркетинг и маркетинговые исследования. 2018. № 3. С. 170-179.

Скоробогатых И.И., Мусатова Ж.Б. Особенности поведения «цифровых» потребителей // Проблемы современной экономики. 2018. № 4 (68). С. 127-130.

Скоробогатых И.И., Мусатова Ж.Б. Поколение «цифровых» потребителей в системе маркетинга 4.0 // Экономика в меняющемся мире: сб. науч. ст. Казань: Изд-во Казанск. (Приволжск.) федеральн. ун-та, 2019. С. 232-235.

Смирнов Ю.Н., Шадрова Ю.В. Методология управления маркетинговой деятельностью промышленного предприятия // Научно-практический журнал «Интеграл». 2010. № 5. С. 84-85.

Татаринов К.А. Клиенты как маркетинговый ресурс онлайн-компании // Азимут научных исследований: экономика и управление. 2019. Т. 8. № 1 (26). С. 313-316.

Федюнин Д.В., Шилина М.Г. Цифровая экономика и новые парадигмы практик и теории PR // Российская школа связей с общественностью. 2019. № 12. С. 55-66.

Халин В.Г., Чернова Г.В. Цифровизация и ее влияние на российскую экономику и общество: преимущества, вызовы, угрозы и риски // Управленческое консультирование. 2018. № 10 (118). С. 46-63.

Холод М.В. Форсайт-методы для определения приоритетных направлений развития цифровой экономики // Экономика и управление народным хозяйством: генезис, современное состояние и перспективы развития: мат. II Междунар. науч.-практ. конф.: в 2 ч. 2018. Ч. 2. С. 291-295.

Ценностные ориентиры и потребительские предпочтения молодежной аудитории /под ред. А.В. Цветковой М.: Креативная экономика, 2017.

Цифровая экономика: глобальные тренды и практика российского бизнеса / под ред. Д. Медовникова. М.: НИУ ВШЭ, 2018.

Чумиков А., Горошко Е., Корнев M. PR, реклама, журналистика в Интернете: теория и практика: учеб. пособие. М.: Аргамак-Медиа, 2019.

Шилина М.Г., Вартанов С.А. Доверие как категория теории коммуникации в парадигме цифровой экономики (к постановке научной проблемы) // МедиаАльманах. 2019. № 1. C. 20-38. DOI: 10.30547/mediaalmanah.1.2019.2038

Шилина М.Г. Корпоративные интернет-ресурсы в системе общественных связей: структура, содержание, особенности развития: дис. ... канд. филол. наук. М., 2007.

Шилина М.Г. (а) Рынок PR-услуг в России в период кризиса: объем, субъекты, специализации // Медиаскоп. 2016. Вып. 2. Режим доступа: http://www.mediascope.ru/ node/2119 
Шилина М.Г. Текстогенные трансформации инфосферы. Методологический эскиз становления Интернета: моногр. М.: РИЦ «Северо-Восток», 2012.

Шилина М.Г. Технологии искусственного интеллекта в стратегической коммуникации: актуальные российские реалии // Альманах «Российские связи с общественностью». 2019. № 15. С. 12-28.

Шилина М.Г. (б) Big \& Open Data как фактор трансформации профессиональной социальной коммуникации? // Коммуникация. Медиа. Дизайн. 2016. № 3. С. 19-33.

Шишкина М.А. Паблик рилейшнз в системе социального управления. СПб: Издво СПбГУ, 1999.

Штомпка П. Доверие - основа общества / пер. с пол. Н.В. Морозовой. М.: Логос, 2012.

Экономика и социология доверия / под ред. В. Веселова. СПб: Социологическое общ-во им. М.М. Ковалевского, 2004.

Юлдашева О.У. Когнитивный подход к формированию потенциального спроса на товары и услуги фирмы // Вестн. С.-Петербургск. ун-та. Сер. 8: Менеджмент. 2006. Вып. 2. С. 130-149.

Юлдашева О.У., Окольнишникова И.Ю. Персонализация маркетинговых коммуникаций - ориентир адаптации маркетинг-микса к требованиям потребителей в условиях информатизации общества // Маркетинговые коммуникации. 2012. № 4 (70). С. 204-212.

Couldry N., Mejias U. (2019) The Costs of Connection. Stanford University Press.

Davidson S. (2016), Public Relations Theory. An Agonistic Critique of the Turns to Dialogue and Symmetry. Public Relations Inquiry 5 (2): 145-167.

Falkheimer J., Heide M. (2018) Strategic Communication. Routledge.

Flyverbom M., Deibert R., Matten D. (2019) The Governance of Digital Technology,

Big Data, and the Internet. New Roles and Responsibilities for Business. Business\&Society 58 (1): 3-19. DOI: 10.1177/0007650317727540

Foucault M. (1975) Surveiller et punir: Naissance de la prison. Paris: Gallimard.

Gentsch P. (2019a) Al in Marketing, Sales and Service. How Marketers without a Data Science Degree Can Use Al, Big Data and Bots. Palgrave Macmillan.

Gentsch P. (2019b) Conversational Al: How (Chat)Bots Will Reshape the Digital Experience: How Marketers without a Data Science Degree can use Al, Big Data and Bots. In: Al in Marketing, Sales and Service, pp. 81-125.

Gladkova A., Ragnedda M. (2019) Digital Divide as a Social Problem: The Case of Russian Regions. In: Digitalizing Media: Communication, Audiences, Policies. The 11 th International Media Readings in Moscow "Mass Media and Communications 2019". Moscow, pp. 59-61.

Grant R.H. (2016) Contemporary Strategy Analysis. 9 ed. Wiley Publishing.

Grunig E.J., Hunt T. (1984) Managing Public Relations. N.Y.: Holt, Rinehart\&Winston.

Grunig J., Grunig L., Toth E. (eds.) (2006) The Future of Excellence in Public Relations and Communication Management: Challenges for the Next Generation. Routledge.

Hallahan K., Holtzhausen D., Van Ruler B., Vercic D. et al. (2007) Defining Strategic Communication. International Journal of Strategic Communication 1: 3-35.

Han B.-C. (2015) The Transparency Society. Stanford, CA: Stanford University Press.

Holtzhausen D.R. (2016) Datafication: Threat or Opportunity for Communication in the Public Sphere? Journal of Communication Management 20 (1): 21-36. DOI: 10.1108/JCOM-12-2014-0082 
Holtzhausen D.R., Zerfass A. (2015) Strategic communication: Opportunities and Challenges of the Research Area. In: Holtzhausen D.R. Zerfass A. (eds.) The Routledge Handbook of Strategic Communication. New York, NY: Routledge, pp. 3-17.

Huang Y.-H.C., Wu F., Huang Q. (2017) Does Research on Digital Public Relations Indicate a Paradigm Shift? An Analysis and Critique of Recent Trends. Telematics and Informatics 34 (7): 1364-1376. DOI: 10.1016/j.tele.2016.08.012

Ihlen $\emptyset$., Fredriksson M. (eds.) (2018) Public Relations and Social Theory: Key Figures, Concepts and Developments. 2 ed. New York, NY: Routledge.

Kuzheleva-Sagan I.P., Suchkova N.A. (2016) Designing Trust in the Internet Services . Al \& Soc 31 (3): 381-392. DOI: 10.1007/s00146-015-0622-7

Luhman N. (1979) Trust and Power. Chichester: Wiley.

Manovich L. (2015) The Science of Culture? Social Computing, Digital Humanities and Cultural Analytics. Manovich. Режим доступа: http://manovich.net/content/04projects/088-cultural-analytics-social-computing/cultural_analytics_article_final.pdf (дата обращения: 23.04.2018).

Mesenbourg T.L. (2001) Measuring the Digital Economy. U.S.: Bureau of the Census.

Negroponte N. (1996). Being Digital. Knopf. Paperback edition.

Neumann W.R. (2008) Interaction. In: Donsbach W. (ed.) The International Encyclopedia of Communication. Malden, MA: Blackwell, vol. V, pp. 2305-2309.

Nothhaft H. (2016) A Framework for Strategic Communication Research: A Call for Synthesis and Consilience. International Journal of Strategic Communication 10 (2): 69-86. DOI: 10.1080/1553118X.2015.1124277

Nothhaft H., Werder K.P., Verčič D., Zerfass A. (eds.) (2019) Future Directions of Strategic Communication. Routledge.

Pagallo U. (2017) The Legal Challenges of Big Data: Putting Secondary Rules First in the Field of EU Data Protection. European Data Protection Law Review 3 (1): 36-46. DOI: 10.21552/edpl/2017/1/7

Paul C. (2011) Strategic Communication: Origins, Concepts, and Current Debates. Santa Barbara, CA: Praeger.

Schiller D. (1999) Digital Capitalism. Networking the Global Market System. The MIT Press. Cambridge, US.

Shilina M., Gorokhov V. (2019) Digital Datafied Divide: New (Corpo)realities, Levels and Effects in Phygital Communication. In: Digitalizing Media: Communication, Audiences, Policies. The 11 th International Media Readings in Moscow "Mass Media and Communications 2019". Moscow, pp. 136-138.

Shilina M.G., You K. (2019) Data-driven Asymmetry of Communication on Digital Economy and Datafied Society. In: Les communications a l'epoque de transformation numerique. Paris: L'Harmattan, pp. 147-151.

Tapscott D. (1997) The Digital Economy: Promise and Peril in the Age of Networked Intelligence. McGraw-Hill; 1 ed.

van Ruler B. (2018) Communication Theory: An Underrated Pillar on Which Strategic Communication Rests. International Journal of Strategic Communication 12 (4): 367-381. DOI: 10.1080/1553118X.2018.1452240

van Ruler B., Korver Fr. (2019) The Communication Strategy Handbook. NY.: Peter Lang Publishing. V 
van Ruler B., Verčič, D. (eds.) (2004) Public Relations and Communication Management in Europe. De Gruyter.

Verčič D., Verčič A.T., Sriramesh K. (2015) Looking for Digital in Public Relations. Public Relations Review 41 (2): 142-152.

West S.M. (2019) Data Capitalism. Redefining the Logics of Surveillance and Privacy. Business\&Society 58 (1): 20-41. DOI: 10.1177/0007650317718185

Wiesenberg M., Tench R. (2019) Deep Strategic Mediatization: Organizational Leaders' Knowledge and Usage of Social Bots in an Era of Disinformation. International Journal of Information Management. DOI: 10.1016/j.ijinfomgt.2019.102042

Wiesenberg M., Zerfass A., Moreno A. (2017) Big Data and Automation in Strategic Communication. International Journal of Strategic Communication 11 (2): 95-114. DOI: 10.1080/1553118X.2017.1285770

Zerfass A., Huck S. (2007) Innovation, Communication, and Leadership: New Developments in Strategic Communication. International Journal of Strategic Communication 1 (2): 107-122. DOI: 10.1080/15531180701298908

Zerfass A., Verčič D. Verhoeven P., Moreno A. et al. (2019) European Communication Monitor 2019. Exploring Trust in the Profession, Transparency, Artificial Intelligence and New Content Strategies. Results of a survey in 46 countries. Brussels: EACD/EUPRERA, Quadriga Media Berlin. Режим доступа: http://www.communicationmonitor.eu/wp-content/uploads/ dlm_uploads/ECM19-Facts-1.pdf (дата обращения: 01.12.2019).

Zuboff S. (2019) The Age of Surveillance Capitalism: The Fight for a Human Future at the New Frontier of Power. 1 ed. New York: PublicAffairs. 